\title{
Simplified total arch repair with a stented graft for acute DeBakey type I dissection
}

\author{
Enyi Shi, MD, PhD, Tianxiang Gu, MD, PhD, Yang Yu, MD, Chun Wang, MD, PhD, Lei Yu, MD, \\ Qin Fang, MD, and Yuhai Zhang, MD, PhD
}

Objective: A novel technique for total arch repair was developed, and the safety and feasibility of this simplified technique were compared with those of total arch replacement.

\begin{abstract}
Methods: With the use of a self-designed stented graft, of which the proximal $10 \mathrm{~cm}$ is free of stent, 54 patients with acute type I dissection underwent ascending aorta replacement combined with total arch repair (simplified group). The stented part was implanted into the descending aorta as an elephant trunk, and the part free of stent was sutured inside the arch with exposure of the orifices of $3 \mathrm{arch}$ vessels. A total of 41 patients with acute type I dissection undergoing ascending aorta and total arch replacement with stented elephant trunk (total arch group) were enrolled as controls.
\end{abstract}

Results: There was no permanent neurologic dysfunction or paraplegia in both groups. The incidence of postoperative transient neurologic dysfunction and prolonged ventilation was lower in the simplified group $(P<.05)$. The hospital mortality was 3.7\% (2/54) in the simplified group and $7.3 \%(3 / 41)$ in the total arch group $(P=.44)$. No significant difference was detected in survival between the 2 groups $(P=.78)$. Complete thrombosis in the false lumen of the residual arch was found in all patients undergoing simplified aortic repair. The rate of complete thrombosis in the false lumen of the distal aorta was similar between the 2 groups $(P>.05)$. The risks of aortic event were comparable for both groups $(P=.84)$.

Conclusions: The simplified technique of total arch repair is an easy and effective surgical strategy for acute type I dissections. (J Thorac Cardiovasc Surg 2014;148:2147-54)

Acute DeBakey type I aortic dissection is a life-threatening cardiovascular disease that frequently requires surgical treatment. Although ascending aorta or hemiarch replacement is believed to be sufficient for saving patients' lives in most cases,${ }^{1-3}$ the untreated false lumen of the distal aorta may expose patients to the risk of aortic rupture or repeat intervention. Replacement of the ascending aorta and total arch has been recommended for type I aortic dissections by some authors because of the satisfactory long-term results, especially for patients with the intimal tear in the arch or the proximal descending aorta. ${ }^{4-7}$ Despite the advances of surgical techniques and perfusion strategies, the complex procedure of total arch replacement continues to be a great challenge for cardiac surgeons. A long cardiopulmonary bypass (CPB), hypothermic circulatory arrest (HCA), and antegrade selective cerebral perfusion (SCP) may be the most important factors contributing to

\footnotetext{
From the Department of Cardiac Surgery, First Affiliated Hospital, China Medical University, Shenyang, China.

Disclosures: Authors have nothing to disclose with regard to commercial support.

Received for publication Dec 10, 2013; revisions received Jan 27, 2014; accepted for publication Feb 26, 2014; available ahead of print March 31, 2014.

Address for reprints: Tianxiang Gu, MD, PhD, Department of Cardiac Surgery, First Affiliated Hospital, China Medical University, Shenyang 110001, P. R. China (E-mail: cmugtx@sina.com).

$0022-5223 / \$ 36.00$

Copyright (C) 2014 by The American Association for Thoracic Surgery

http://dx.doi.org/10.1016/j.jtcvs.2014.02.077
}

the postoperative complications. By weighing the benefits and risks, some simplified strategies rather than total arch replacement or simple ascending aorta replacement have been introduced to treat acute type I dissections, and the results are encouraging. ${ }^{8-11}$

A novel procedure was designed for total arch repair of acute type I dissections at First Affiliated Hospital. Such a procedure was performed by using a self-designed stented graft, of which the proximal free edge is lengthened to $10 \mathrm{~cm}$. The stented part was implanted into the descending aorta as a stented elephant trunk, and the part free of stent was located inside the residual arch for total arch repair. Direct anastomoses of the graft to 3 arch vessels and the distal descending aorta were no longer needed in such a procedure. In this article, we highlight this simplified technique for total arch repair in acute type I aortic dissections, and the safety and feasibility are evaluated by comparing with those of total arch replacement with stented elephant trunk implantation.

\footnotetext{
METHODS

Patients

From February 2010 to December 2012, 141 patients with acute type I dissection received surgical treatment in the Department of Cardiac Surgery. All diagnoses were made by computed tomography angiography (CTA) or magnetic resonance angiography. Three branches of the arch were confirmed to be free of dissection on CTA or magnetic resonance angiography in 127 cases. For these patients, our newly simplified surgical
} 


\section{Abbreviations and Acronyms \\ $\mathrm{CPB}=$ cardiopulmonary bypass \\ $\mathrm{CTA}=$ computed tomography angiography \\ $\mathrm{HCA}=$ hypothermic circulatory arrest \\ $\mathrm{SCP}=$ selective cerebral perfusion}

procedure was performed in 54 patients (simplified group), and total arch replacement accompanied by the stented elephant trunk technique was performed in 41 patients (total arch group). The operative procedure of simplified aortic arch repair or total arch replacement was selected by the surgeon according to the patient's condition. All the surgeries were performed by the same surgeon (T.G.). This retrospective study was approved by the Ethics Committee of the First Affiliated Hospital, China Medical University. The demographic and preoperative data of the patients are listed in Table 1.

\section{Surgical Procedure}

A median sternotomy was performed, and the innominate $\operatorname{artery}^{8}$ or right axillary artery was used for systemic perfusion and SCP. Venous return was established with a 2 -stage cannula introduced via the right atrium. When the patient was cooled to $32^{\circ} \mathrm{C}$, the aorta was clamped just proximal to the innominate artery. After a careful inspection of the aortic valve and the coronary ostia, a decision was made about the subsequent root procedure. Supracommissural aortic replacement was performed with a suitable vessel prosthesis whenever the root was not involved in the dissection and no aortic insufficiency was present. If the aortic regurgitation was severe, the Bentall, Wheat, or David procedure was performed according to whether the coronary ostia were affected by the dissection. During this period, the body temperature was continually decreased. After the proximal procedure was accomplished with reaching the anticipated HCA bladder temperature of $25^{\circ} \mathrm{C}$, circulation was arrested. Then SCP was performed with a rate of 8 to $10 \mathrm{~mL} \cdot \mathrm{kg}^{-1} \cdot \mathrm{min}^{-1}$.

For patients undergoing the simplified arch repair, the arch was transected obliquely. All of the greater curvature of the arch was reserved, whereas most of the lesser curvature was resected. A self-expandable stented graft was used (MicroPort Medical Co, Ltd, Shanghai, China) (Figure 1). The self-expandable metal stent is made of elastic alloy for medical use. A polyester vascular graft is sewn and attached outside the stent with a $10-\mathrm{cm}$ free edge at the proximal end. The stented part of the stented graft was implanted anterogradely into the true lumen of descending aorta, and the vascular graft free of stent was located inside the residual native arch. According to the arch incision, the redundant vascular graft was pruned away. The greater curvature of the vascular graft was cut longitudinally to fully expose the orifices of 3 vessels. A continuous suture (4-0 Prolene) was performed inside the residual arch and ran through the entire native vessel wall around the orifices of the 3 branches to attach the vascular graft to the native arch. SCP was stopped transiently if too much blood returning from the left carotid artery and left subclavian artery was unfavorable for suturing. The distal end of the vessel prosthesis for replacement of the ascending aorta was trimmed as a suitable shape. The anastomosis of the proximal and distal vascular grafts combined with the native vessel wall of aortic arch was accomplished with a continuous suture (4-0 Prolene) using an open aortic technique. The surgical procedure is illustrated in Figure 2.

For patients undergoing total arch replacement, the ascending aorta and transverse arch were opened. The distal aorta was transected circumferentially close to the proximal margin of the origin of the left subclavian artery. The stent vessel prosthesis (MicroPort Medical Co, Ltd) was similar to that used in the simplified group, except the free edge was only $1 \mathrm{~cm}$ and then inserted into the true lumen of the descending aorta. The anastomosis between the 4-branched prosthetic graft and the distal aorta containing the intraluminal stented graft was carried out using the open aortic technique. After the anastomosis was completed, blood perfusion of the lower body was started via the perfusion limb of the 4-branched prosthetic graft. During rewarming, the left subclavian artery, left common carotid artery, and innominate artery were anastomosed to the respective limbs of the 4-branched prosthetic graft in an end-to-end style.,

\section{Stent Graft Selection}

The diameter of the selected stent graft should be $2 \mathrm{~mm}$ larger than that of the native mid-arch (between the left carotid and left subclavian arteries), which was measured during the operation. The diameter of the native proximal descending aorta also needs to be taken into consideration. The proximal end of the stent was positioned just distal to the origin of the left subclavian artery. The diameter of the stent ranged from 26 to $32 \mathrm{~mm}$, and the length was 80 to $100 \mathrm{~mm}$. The most preferable size of the stent graft was 28 to $30 \mathrm{~mm} .^{5,8}$

\section{Neurologic Dysfunction Evaluation}

A permanent neurologic dysfunction was defined as stroke confirmed by conventional imaging techniques. A temporary neurologic dysfunction was defined as subtle but diffused brain injury and was classified into 5 grades ${ }^{12}$ (Table 2). Neuropsychologic evaluation was performed postoperatively in each patient by a neurologist.

\section{Follow-up}

The follow-up data were obtained by clinical interviews or phone interviews conducted according to a standardized questionnaire. CTA was performed before discharge, 3 months after the surgery, and every 6 months thereafter. An aortic event was defined as reintervention for the residue aorta pathology or distal aortic dilatation with a maximal diameter of more than $55 \mathrm{~mm}$.

\section{Statistical Analysis}

Categoric variables are presented as percentages and were analyzed using the chi-square test. Continuous variables are expressed as mean \pm standard deviation and were analyzed using the Student $t$ test. Statistical analysis of the neurologic scores was performed with the Mann-Whitney $U$ test. The actuarial survival and freedom from aortic event were calculated using the Kaplan-Meier method, followed by the log-rank test.

TABLE 1. Demographic and preoperative data

\begin{tabular}{lccc}
\hline & $\begin{array}{c}\text { Simplified } \\
(\mathbf{n}=\mathbf{5 4})\end{array}$ & $\begin{array}{c}\text { Total arch } \\
(\mathbf{n}=\mathbf{4 1})\end{array}$ & $\begin{array}{c}\boldsymbol{P} \\
\text { value }\end{array}$ \\
\hline Male & $37(68.5 \%)$ & $22(53.7 \%)$ & .14 \\
Age (y) & $59.7 \pm 12.9$ & $57.4 \pm 10.7$ & .36 \\
Marfan syndrome & $19(35.2 \%)$ & $17(41.6 \%)$ & .53 \\
Preoperative comorbidities & & & \\
$\quad$ Hypertension & $40(74.1 \%)$ & $29(70.7 \%)$ & .72 \\
Hyperlipidemia & $8(14.8 \%)$ & $9(22.0 \%)$ & .37 \\
Diabetes & $13(24.1 \%)$ & $10(24.4 \%)$ & .97 \\
History of CVA & $2(3.7 \%)$ & $2(4.9 \%)$ & .79 \\
Hypoxemia & $7(13.0 \%)$ & $11(26.6 \%)$ & .09 \\
Renal failure & $3(5.6 \%)$ & $1(2.4 \%)$ & .45 \\
$\quad($ creatinine $>2.0 \mathrm{mg} / \mathrm{dL})$ & & & \\
$\quad$ Tamponade & $10(18.5 \%)$ & $7(17.1 \%)$ & .86 \\
Coronary heart disease & $2(3.7 \%)$ & $3(7.3 \%)$ & .44 \\
Aortic regurgitation & $23(42.6 \%)$ & $15(36.6 \%)$ & .55 \\
$\quad$ (moderate to severe) & & & \\
\hline
\end{tabular}

CVA, Cerebrovascular accident. 


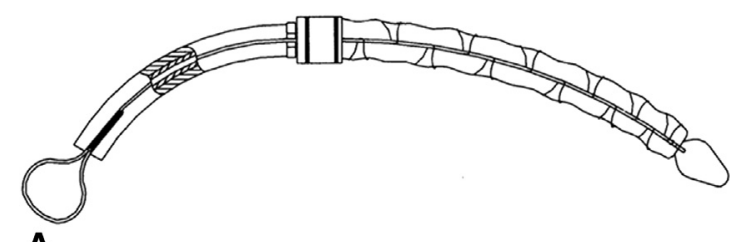

A

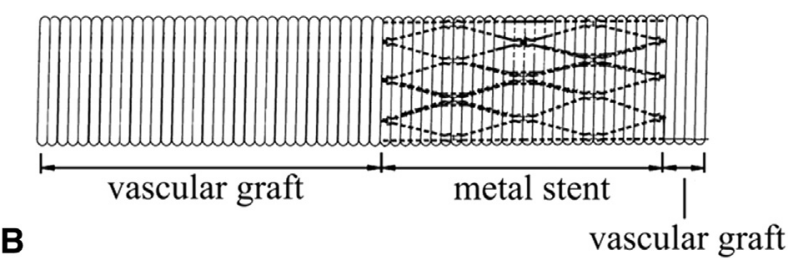

FIGURE 1. Sketch of the self-designed stented elephant graft and delivery system. A, Stented graft before delivery. B, Stented graft in expanded state.

\section{RESULTS}

\section{Intraoperative and Postoperative Data}

The intraoperative and postoperative variables of the 2 groups are shown in Table 3. No significant differences of the aortic root procedures and concomitant surgeries were found between the simplified group and the total arch group $(P>.05$, respectively). The intimal tears were identified in the arch in 14 patients undergoing simplified aortic arch, and the tears were resected completely in 4 patients.
Although the ratio of the tears in arch was higher in the total arch group, the difference did not reach statistical significance $(P=.07)$. The durations of $\mathrm{CPB}$, crossclamping, and SCP were significantly shorter in the simplified group than in the total arch group $(P<.01)$. The incidence of prolonged ventilation was significantly decreased in patients undergoing the simplified procedure $(P=.03)$. No marked differences were detected in the incidences of dialysis, low cardiac output syndrome, or sepsis between the 2 groups $(P>.05)$. No permanent neurologic dysfunction, paraplegia, or paralysis occurred in the whole cohort. No patient underwent reoperation for hemostasis. The score of temporary neurologic dysfunction in the simplified group was significantly lower than that in the total arch group $(P=.02)$. The hospital deaths were $2(3.7 \%)$ in the simplified group and $3(7.3 \%)$ in the total arch group $(P=.44)$. Postoperative aortic CTA showed that no blood was detected to flow back along the stented part and accumulate around the graft in the arch region in patients receiving simplified arch repair (Figure 3).

\section{Follow-up}

A total of 90 patients were discharged; 6 patients in the simplified group and 2 patients in the total arch group were lost during follow-up $(P=.30)$. The average durations
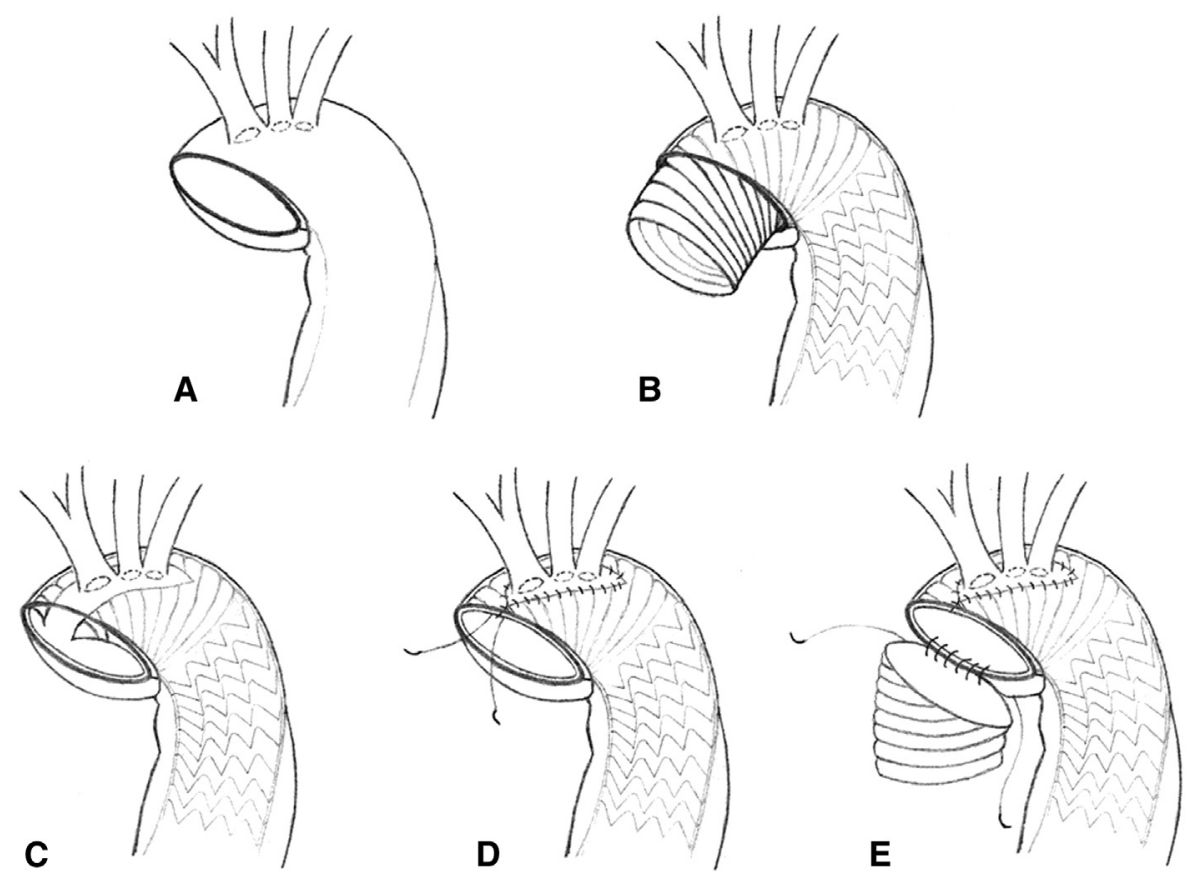

FIGURE 2. Diagram of the simplified technique. A, The arch is transected obliquely, and almost all of the lesser curvature is resected. The distal hemiarch is reserved. B, The stented part of the graft is implanted into the descending aorta with the proximal edge of the stent just distal to the origin of left subclavian artery, and the graft free of stent is located inside the reserved arch. C, According to the arch incision, the redundant vascular graft outside the arch is pruned away. The greater curvature of the vascular graft is cut to expose the orifices of 3 vessels. D, A continuous suture is performed around the orifices of 3 branches to attach the vascular graft to the native aortic arch. E. The anastomosis of the proximal and distal vascular grafts combined with the native vessel wall of aortic arch is accomplished with a continuous suture using an open aortic technique. 
TABLE 2. Clinical scale for temporary neurologic dysfunction

\begin{tabular}{clc}
\hline Grade & & Duration \\
\hline Grade 0 & Normal & \\
Grade 1 & Simple confusion & Short $(<48$ h) \\
Grade 2 & Confusion + lethargy & Short \\
Grade 3 & Confusion + agitation & Short $(<72 \mathrm{~h})$ \\
Grade 4 & Overt psychosis & Long $(>72 \mathrm{~h})$ \\
Grade 5 & Psychosis, parkinsonism & Long \\
\hline
\end{tabular}

of follow-up time were $24.0 \pm 9.4$ months for the simplified group and $24.7 \pm 10.8$ months for the total arch group $(P=.74)$. All late deaths in the whole cohort were attributed to nonaortic reasons (Table 4). A small endoleak from the left subclavian artery was detected in 1 patient undergoing simplified aortic repair, and no reintervention was performed except a close follow-up (Figure 4).

The overall 3-year survival (excluding hospital deaths) of the whole cohort was $85.4 \%$ (Figure 5). Figure 6 demonstrates the survival function of the 2 groups, and no

TABLE 3. Surgical procedure, intraoperative, and postoperative data

\begin{tabular}{|c|c|c|c|}
\hline & $\begin{array}{c}\text { Simplified } \\
(\mathrm{n}=54)\end{array}$ & $\begin{array}{c}\text { Total arch } \\
(\mathrm{n}=\mathbf{4 1})\end{array}$ & $\begin{array}{c}P \\
\text { value }\end{array}$ \\
\hline \multicolumn{4}{|l|}{ Intimal tearing sites } \\
\hline Ascending aorta & $20(37.0 \%)$ & $11(26.8 \%)$ & .29 \\
\hline Arch & $14(25.9 \%)$ & $18(43.9 \%)$ & .07 \\
\hline Proximal descending aorta & $11(20.4 \%)$ & $7(17.1 \%)$ & .69 \\
\hline Unidentified & $9(16.7 \%)$ & $5(12.2 \%)$ & .54 \\
\hline \multicolumn{4}{|l|}{ Aortic root surgery } \\
\hline Bentall procedure & $15(27.8 \%)$ & $8(19.5 \%)$ & .35 \\
\hline Wheat procedure & $5(9.3 \%)$ & $4(9.8 \%)$ & .94 \\
\hline David & $3(5.6 \%)$ & $3(7.3 \%)$ & .73 \\
\hline \multicolumn{4}{|l|}{ Concomitant procedures } \\
\hline MV repair/replacement & $2(3.7 \%)$ & $1(2.4 \%)$ & .73 \\
\hline CABG & $2(3.7 \%)$ & $3(7.3 \%)$ & .44 \\
\hline CPB time (min) & $95.7 \pm 17.7$ & $158.1 \pm 21.2$ & $.00^{*}$ \\
\hline Crossclamp time (min) & $75.8 \pm 15.6$ & $110.4 \pm 21.4$ & $.00^{*}$ \\
\hline HCA time (min) & $28.5 \pm 2.9$ & $29.8 \pm 4.9$ & .09 \\
\hline SCP time (min) & $26.9 \pm 2.3$ & $53.2 \pm 6.5$ & $.00^{*}$ \\
\hline Lowest rectal temperature $\left({ }^{\circ} \mathrm{C}\right)$ & $23.3 \pm 1.6$ & $23.7 \pm 1.3$ & .20 \\
\hline Reoperation for hemostasis & 0 & 0 & \\
\hline Ventilation time $>72 \mathrm{~h}$ & $4(7.4 \%)$ & $9(22.0 \%)$ & $.04^{*}$ \\
\hline LCOS & $2(3.7 \%)$ & $5(12.2 \%)$ & .12 \\
\hline Dialysis & $4(7.4 \%)$ & $8(19.5 \%)$ & .08 \\
\hline \multicolumn{4}{|l|}{ Temporary neurologic dysfunction } \\
\hline Grade 1 & 5 & 9 & \\
\hline Grade 2 & 3 & 4 & \\
\hline Grade 3 & 1 & 2 & \\
\hline Grade 4 & 0 & 1 & $.02 *$ \\
\hline Permanent neurologic dysfunction & 0 & 0 & \\
\hline Paraplegia or paralysis & 0 & 0 & \\
\hline Infection or sepsis & $1(1.9 \%)$ & $1(2.4 \%)$ & .84 \\
\hline Hospital mortality & $2(3.7 \%)$ & $3(7.3 \%)$ & .44 \\
\hline
\end{tabular}

$C A B G$, Coronary artery bypass graft; $C P B$, cardiopulmonary bypass; $H C A$, hypothermia circulatory arrest; $L C O S$, low cardiac output syndrome; $M V$, mitral valve; $S C P$, selective antegrade cerebral perfusion. $* P<.05$. significant difference was detected $(P=.78)$. False lumen at the arch was decreased with complete thrombosis in all patients receiving simplified arch repair during follow-up (Table 5), and no significant dilation in the residual arch was found, including the patients with Marfan syndrome. No reintervention was performed because of the residue native arch during follow-up. The behavior of the false lumen of the descending aorta is listed in Table 5. The rates of complete thrombosis formation at the different levels of distal aorta in the 2 groups were similar at the different time points $(P>.05)$. Enlargement of the distal descending aorta $(>55 \mathrm{~mm})$ was detected in 5 patients (3 patients in the simplified group and 2 patients in the total arch group). The patients refused reintervention for personal reasons and were followed up closely. The 3-year freedom from aortic events was $85.7 \%$ in the simplified group and $89.1 \%$ in the total arch group $(P=.84)$ (Figure 7).

\section{DISCUSSION}

Acute aortic dissections of DeBakey type I conjointly affect the ascending aorta, the arch, and the more distal aorta. The optimal surgical strategy for acute type I dissections spans the more conservative approaches using only replacement of the ascending aorta with or without resection of the intimal tear to more aggressive methods using total replacement of the ascending aorta and aortic arch combined with elephant trunk. ${ }^{1-11}$ To improve the late surgical outcome, simultaneous replacement of the ascending aorta and total arch was suggested by some authors. ${ }^{4-7}$ Although many surgical techniques have been attempted, total arch replacement is still a highly invasive and risky procedure for patients with acute type I aortic dissection, mainly because it requires elaborate anastomoses of 3 arch vessels to the arch graft separately or reimplantation of the branches as an island flap into the arch graft. Anastomosis of the graft to the distal descending aorta is usually difficult because of the deep surgical field and may cause phrenic and recurrent laryngeal nerve injury. Long periods of $\mathrm{CPB}, \mathrm{HCA}$, and SCP also contribute to the postoperative complications of total arch replacement. Therefore, some modifications have been developed to simplify the procedure of total arch replacement. In the report by Kondoh and colleagues, ${ }^{13}$ total arch replacement was accomplished with a long elephant trunk anastomosed at the origin of innominate artery. Open single-branched stent graft placement into the left subclavian artery and the descending aorta and reinforcement of the dissected arch vessel stump with a stent graft neointima also were introduced for an easier, safer procedure for total arch repair. ${ }^{9}$

By using a self-designed stented elephant graft, a simplified technique has been performed for total arch repair in patients with acute type I dissections at the First Affiliated Hospital. The distal stented part of the graft was 

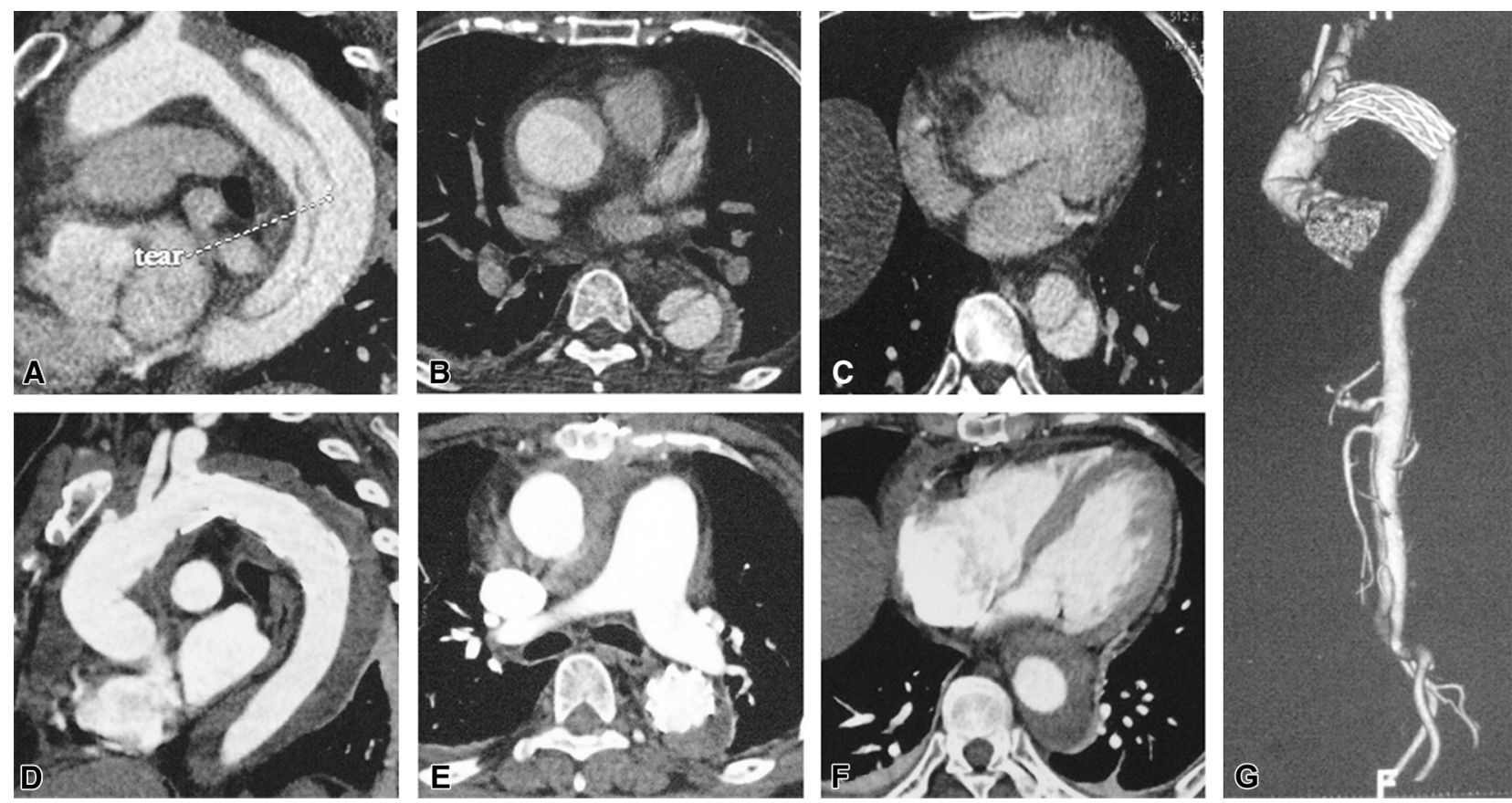

FIGURE 3. CTA of a patient with acute Stanford type I dissection undergoing simplified aortic arch repair before operation (A-C) and 3 months after the surgery (D-G). Preoperative scan shows that the true lumen is compressed by a huge false lumen in the descending aorta (A-C). Postoperative scan shows that the stent graft expanded fully and that the false lumen is almost closed completely with thrombosis throughout the descending aorta. No contrast medium endoleak is detected at the greater curvature of the arch.

implanted into the descending aorta as a "stented elephant trunk," and the arch was repaired by the proximal part free of stent that was attached to the native arch with exposure of the orifices of 3 branches. The key point of this technique was to attach the vascular graft to the native arch tightly. Because the arch was transected obliquely and most of the lesser curvature part was removed, the orifices of 3 branches were well exposed. Therefore, the continuous suture could be accomplished easily around the orifices of 3 vessels. In our series, postoperative endoleak was detected in only 1 patient. A vital advantage of the technique was that the elaborate anastomoses of the graft to the descending aorta and the 3 branches in conventional total arch replacement were avoided. The only anastomosis of the graft for replacement of ascending aorta and the graft inside the arch combined with the native vessel wall of the arch was well exposed to the surgeon, and any bleeding points could be easily controlled. In the current series, such a procedure was easily completed within 30 minutes in

TABLE 4. Late death

\begin{tabular}{lcc}
\hline & Simplified & Total arch \\
\hline Acute cardiac infarction & 1 & 0 \\
Renal failure & 0 & 1 \\
Stroke & 0 & 1 \\
Cerebral hemorrhage & 1 & 1 \\
Pneumonia & 1 & 0 \\
\hline
\end{tabular}

most patients. However, the conventional total arch replacement is more time-consuming. A similar procedure was reported recently by Roselli and colleagues ${ }^{11}$ on a small series of 17 patients. In such a simplified frozen elephant trunk hybrid technique, a stent graft was delivered anterogradely into the opened aorta with the proximal end of the device at the proximal edge of the opened aortic arch. Two of the flares on the stent graft were resected to create a "fenestration" around the supra-aortic branch vessel. The stent graft at the base of this fenestration was then sutured to the base of the branch artery with a pledgeted mattress suture.

The current technique also included implantation of a stented vascular graft into the descending aorta. The stented elephant technique has been well accepted as an optimal strategy for a distal descending aorta in type I dissections. $^{4,8,14,15}$ Compared with the conventional elephant trunk procedure, the stent can maintain the graft fully opened, fix the graft to the native aortic wall, seal the tear located at the distal aorta, compress the false lumen, and enable thrombus obliteration of the downstream false channel. As reported previously, a stent graft $2 \mathrm{~mm}$ larger than the diameter of the native mid-arch was selected, which may further improve the effects of sealing the intimal tear and compressing the false lumen. ${ }^{5,8}$ From the data published thus far, it seems justifiable to implant a stented elephant trunk in type I DeBakey dissections in centers with an expertise in the 

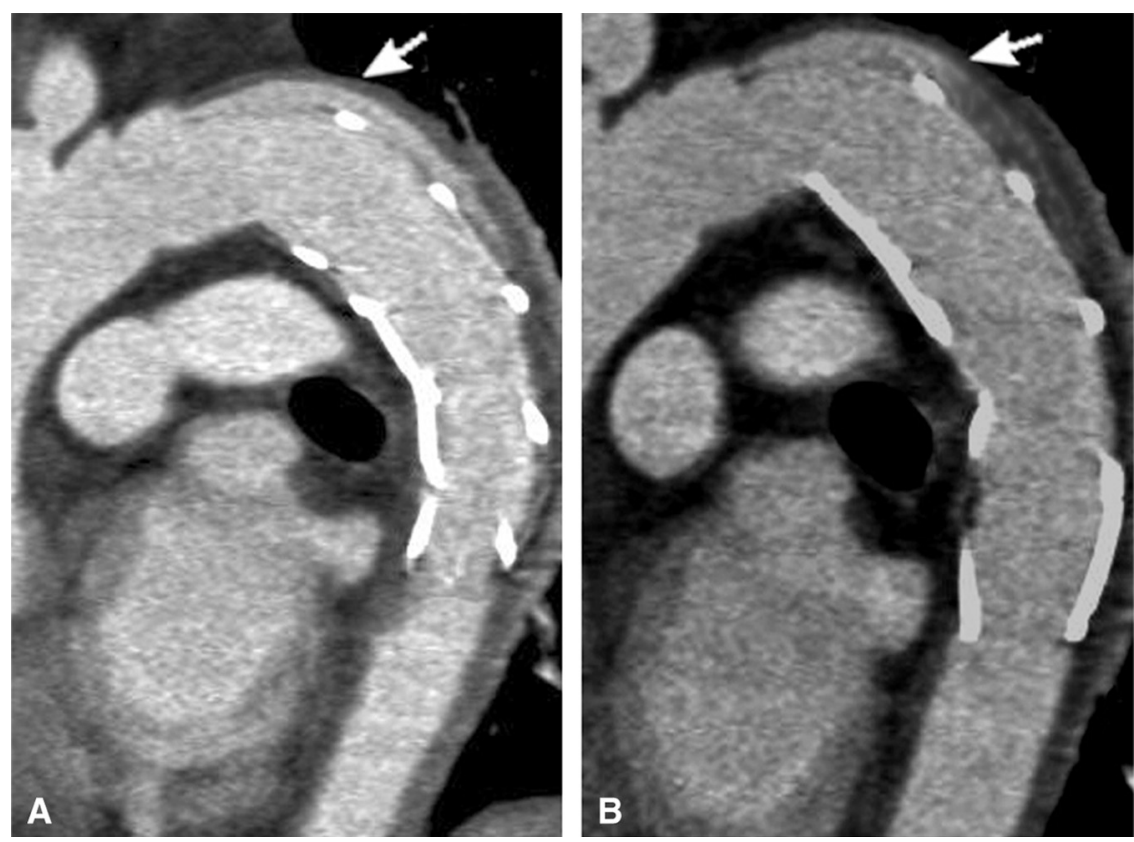

FIGURE 4. Postoperative CTA of a patient undergoing simplified aortic arch repair showing a small endoleak from left subclavian artery (arrows). A, Before discharge. B, Six months after operation.

treatment of aortic diseases. ${ }^{16}$ Tight attachment between the stented part of the prosthesis and the wall of the descending aorta also inhibited the possible flow back of blood along the stented part to the arch region. Therefore, the current procedure was abandoned if the true lumen of the descending aorta was larger than $30 \mathrm{~mm}$. The follow-up showed that the false lumen of the distal aorta was obliterated with thrombus in the majority of patients. The need for secondary intervention of the distal aorta was greatly reduced with the stented elephant trunk technique as

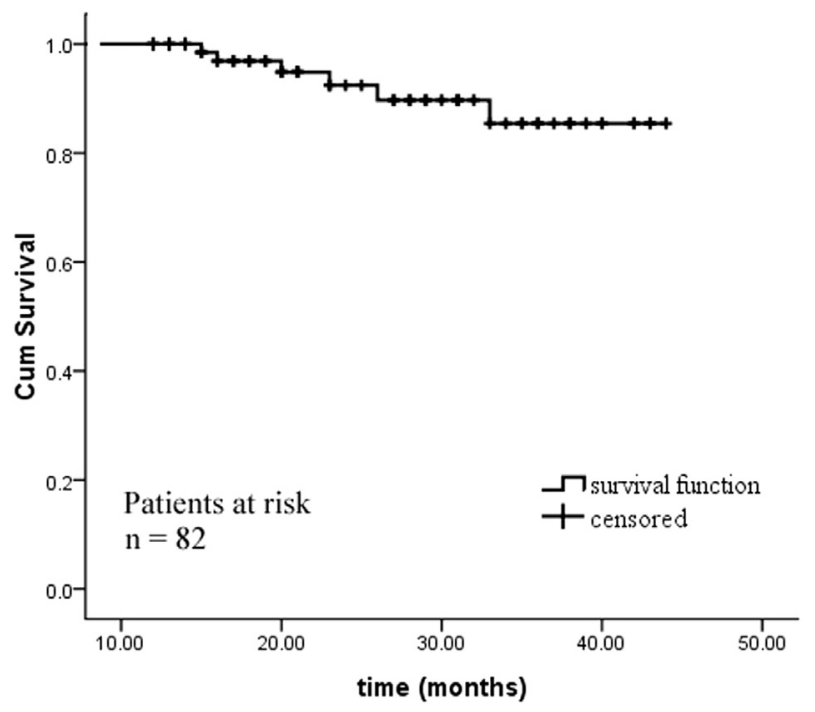

FIGURE 5. Overall survival function of patients with acute DeBakey type I aortic dissection in the whole cohort. demonstrated by long-term follow-up results. ${ }^{17}$ Endoleaks remain an important complication for the stent graft technique. In the current series, endoleak was detected in only 1 patient undergoing simplified aortic arch repair, which is acceptable. Fixation of the graft to the arch using a continuous suture running through the entire native vessel wall around the orifices of the arch branches and the tight attachment between the stent and the native vessel wall

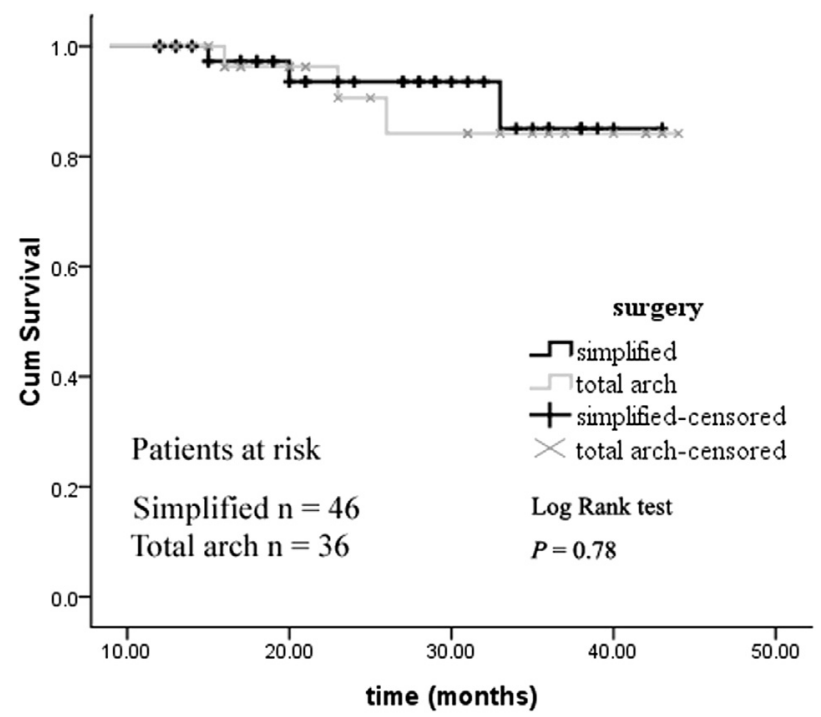

FIGURE 6. Survival of patients with acute DeBakey type I aortic dissection in the simplified group and the total arch group during follow-up. No significant difference was found in survival between the 2 groups $(P=.78)$. 
TABLE 5. Complete thrombosis in the false lumen of the residual arch and descending aorta

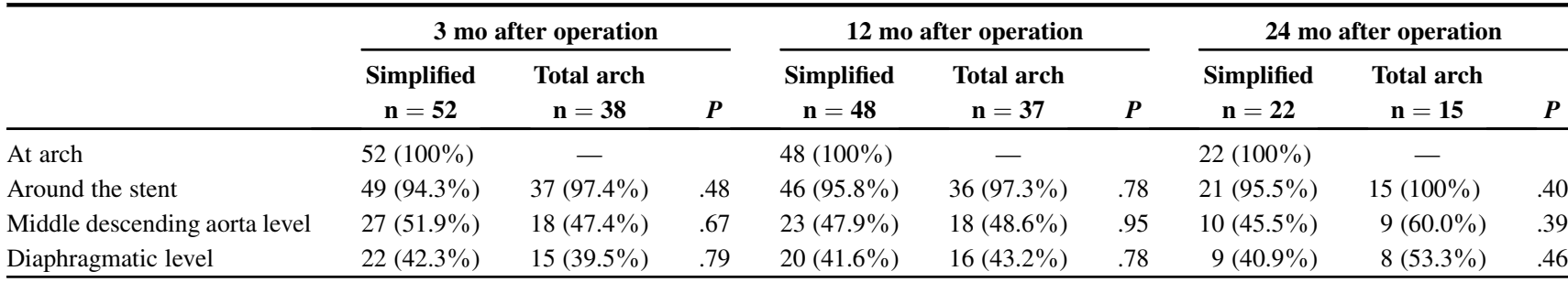

may contribute to the low rate of endoleak in our simplified procedure. A low rate of endoleak was also reported by Roselli and colleagues ${ }^{11}$ using a similar technique.

In the current series, the early and midterm results of the simplified arch repair technique were compared with those of the total arch replacement. No significant differences of the in-hospital mortality were detected between the simplified group and the total arch group. Some newly published literature also indicated that total arch replacement can be performed with a mortality equal to that of some conservative surgical strategy. ${ }^{15,18-20}$ However, the surgical risks were decreased in some degree in the simplified group as evidenced by the lower incidence of prolonged ventilation and transient neurologic dysfunction. The longer periods of $\mathrm{CPB}$, crossclamping, and SCP that are inevitable in total arch surgery may be directly related to cardiac and cerebral injury, as well as organ dysfunction. In the current study, no permanent neurologic dysfunction was found. SCP combined with HCA was used as a strategy for cerebral protection in the whole cohort, which may contribute to the excellent outcomes of neurologic function in the current study. ${ }^{4-8}$ The survival functions of

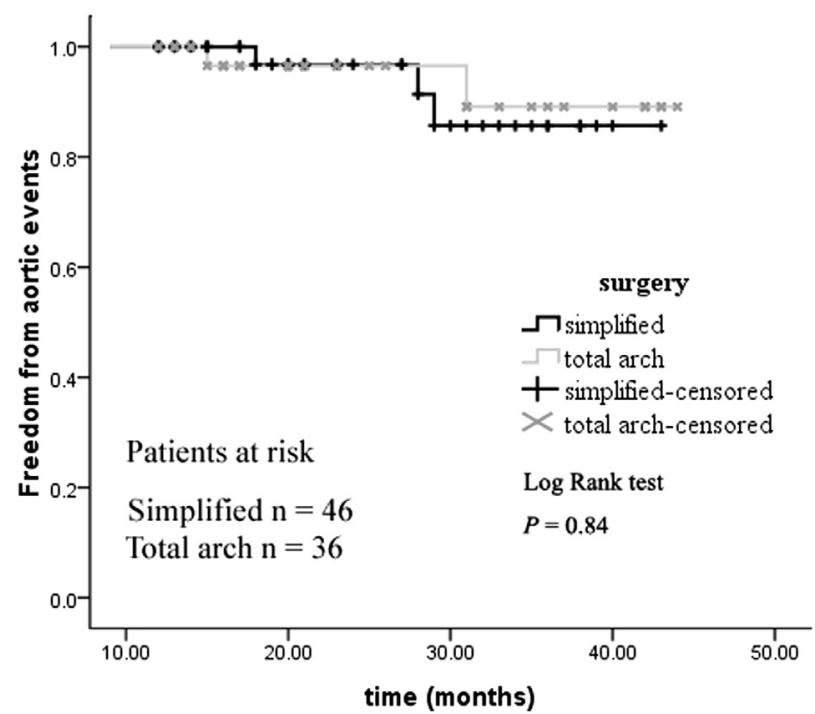

FIGURE 7. Freedom from aortic event of patients with acute DeBakey type I aortic dissection in the simplified group and the total arch group during follow-up. The aortic event rate was not significantly different between the 2 groups $(P=.84)$. the simplified group and total arch group were comparable, and no significant differences were detected. The freedom from reintervention or significant dilation of the distal aorta was similar in both 2 groups. The difference between the 2 surgical strategies was that the great curvature and brachiocephalic arteries of the arch were preserved in patients undergoing the simplified technique. Because there was a vascular graft inside the arch with exposure of the branch vessels, the arch was repaired endovascularly as total arch replacement with an en bloc technique. The intimal tear in the arch also can be sealed by the graft inside the arch. In the current study, patients with intimal tear in the arch also were enrolled for simplified aortic arch repair and achieved similar outcomes as conventional total arch replacement.

The indication for the simplified procedure was type I dissection with 3 branches unaffected by the dissection. The intimal tear should be eliminated by ascending aorta replacement and total arch repair or be sealed effectively by the stented graft. The contraindication is that it is difficult to apply the stented elephant trunk in the true lumen of the distal aorta or the true lumen is larger than $30 \mathrm{~mm}$. Complete resection of the entire native arch tissue, which is prone to further dilation, may be more important for patients with Marfan disease, and total arch replacement using branched graft to reconstruct 3 branches of the arch is recommended. ${ }^{21}$ In the current series, 19 patients with Marfan disease underwent the simplified procedure for total arch repair, and the short-term outcome was satisfactory. However, long-term follow-up is necessary to know whether such a procedure for total arch repair is as effective as the total arch replacement by reconstructing the 3 branches of arch separately in Marfan disease.

\section{Study Limitations}

The primary limitations of the current study are that the number of patients was small and the follow-up time was short. This retrospective study is not randomized. The nonrandomized design may have affected the results because of unmeasured confounders, procedure bias, or detection bias. Although the preliminary outcomes of the simplified procedure were encouraging, it is necessary to evaluate the therapeutic effects of such a procedure in more patients with a long-term follow-up. 


\section{CONCLUSIONS}

The current retrospective study demonstrated that for patients with acute DeBakey type I dissection with 3 branches unaffected by the dissection, the simplified total arch repair is easily performed with satisfactory early and midterm outcomes.

\section{References}

1. Ohtsubo S, Itoh T, Takarabe K, Rikitake K, Furukawa K, Suda H, et al. Surgical results of hemiarch replacement for acute type A dissection. Ann Thorac Surg. 2002;74:S1853-6.

2. Westaby S, Saito S, Katsumata T. Acute type A dissection: conservative methods provide consistently low mortality. Ann Thorac Surg. 2002;73:707-13.

3. Shiono M, Hata M, Sezai A, Niino T, Yagi S, Negishi N. Validity of a limited ascending and hemiarch replacement for acute type A aortic dissection. Ann Thorac Surg. 2006;82:1665-9.

4. Sun L, Qi R, Zhu J, Liu Y, Zheng J. Total arch replacement combined with stented elephant trunk implantation: a new "standard" therapy for type a dissection involving repair of the aortic arch? Circulation. 2011;123:971-8.

5. Liu ZG, Sun LZ, Chang Q, Zhu JM, Dong C, Yu CT, et al. Should the "elephant trunk" be skeletonized? Total arch replacement combined with stented elephant trunk implantation for Stanford type A aortic dissection. J Thorac Cardiovasc Surg. 2006;131:107-13.

6. Kazui T, Yamashita K, Washiyama N, Terada H, Bashar AH, Suzuki K, et al. Aortic arch replacement using selective cerebral perfusion. Ann Thorac Surg. 2007;83:S796-8.

7. Kazui T, Yamashita K, Washiyama N, Terada H, Bashar AH, Suzuki T, et al. Usefulness of antegrade selective cerebral perfusion during aortic arch operations. Ann Thorac Surg. 2002;74:S1806-9.

8. Shi E, Gu T, Yu L, Xiu Z, Zhang Z, Wang C, et al. Repair of Stanford type A aortic dissection with ascending aorta and hemiarch replacement combined with stent-graft elephant trunk technique by using innominate cannulation. J Thorac Cardiovasc Surg. 2011;142:1458-63.

9. Chen LW, Wu XJ, Lu L, Zhang GC, Yang GF, Yang ZW, et al. Total arch repair for acute type $\mathrm{A}$ aortic dissection with 2 modified techniques: open single-branched stent graft placement and reinforcement of the dissected arch vessel stump with stent graft. Circulation. 2011;123:2536-41.

10. Chen LW, Lu L, Dai XF, Wu XJ, Zhang GC, Yang GF, et al. Total arch repair with open triple-branched stent graft placement for acute type A aortic dissection: experience with 122 patients. J Thorac Cardiovasc Surg. 2013 Nov 23, [Epub ahead of print].

11. Roselli EE, Rafael A, Soltesz EG, Canale L, Lytle BW. Simplified frozen elephant trunk repair for acute DeBakey type I dissection. J Thorac Cardiovasc Surg. 2013;145(3 Suppl):S197-201.

12. Ergin MA, Uysal S, Reich DL, Apaydin A, Lansman SL, McCullough JN, et al. Temporary neurological dysfunction after deep hypothermic circulatory arrest: a clinical marker of long-term functional deficit. Ann Thorac Surg. 1999;67: 1887-90.

13. Kondoh H, Taniguchi K, Funatsu T, Toda K, Masai T, Takahashi T, et al. Total arch replacement with long elephant trunk anastomosed at the base of the innominate artery: a single-centre longitudinal experience. Eur J Cardiothorac Surg. 2012;42:840-8.

14. Ishihara H, Uchida N, Yamasaki C, Sakashita M, Kanou M. Extensive primary repair of the thoracic aorta in Stanford type A acute aortic dissection by means of a synthetic vascular graft with a self-expandable stent. J Thorac Cardiovasc Surg. 2002;123:1035-40.

15. Uchida N, Shibamura H, Katayama A, Shimada N, Sutoh M, Ishihara H. Operative strategy for acute type a aortic dissection: ascending aortic or hemiarch versus total arch replacement with frozen elephant trunk. Ann Thorac Surg. 2009; 87:773-7.

16. Hagl C, Pichlmaier M, Khaladj N. Elephant trunks in aortic surgery: fresh and frozen. J Thorac Cardiovasc Surg. 2013;145(3 Suppl):S98-102.

17. Pacini D, Tsagakis K, Jakob H, Mestres CA, Armaro A, Weiss G, et al. The frozen elephant trunk for the treatment of chronic dissection of the thoracic aorta: a multicenter experience. Ann Thorac Surg. 2011;92:1663-70.

18. Zhang H, Lang X, Lu F, Song Z, Wang J, Han L, et al. Acute type A dissection without intimal tear in arch: proximal or extensive repair? J Thorac Cardiovasc Surg. 2013 Jun 15, [Epub ahead of print].

19. Easo J, Weigang E, Hölzl PP, Horst M, Hoffmann I, Blettner M, et al. Influence of operative strategy for the aortic arch in DeBakey type I aortic dissection: analysis of the German Registry for Acute Aortic Dissection Type A. J Thorac Cardiovasc Surg. 2012;144:617-23.

20. Shi E, Gu T, Yu Y, Yu L, Wang C, Fang Q, et al. Early and midterm outcomes of hemiarch replacement combined with stented elephant trunk in the management of acute DeBakey type I aortic dissection: comparison with total arch replacement. J Thorac Cardiovasc Surg. 2013 Nov 28, [Epub ahead of print].

21. Sun L, Li M, Zhu J, Liu Y, Chang Q, Zheng J, et al. Surgery for patients with Marfan syndrome with type A dissection involving the aortic arch using total arch replacement combined with stented elephant trunk implantation: the acute versus the chronic. J Thorac Cardiovasc Surg. 2011;142:e85-91. 